УДК $629.5 .03: 621.177$

doi: 10.32620/aktt.2018.5.07

А. П. ШЕВЦОВ ${ }^{1}$, С. С. РИЖКОВ ${ }^{2}$

${ }^{1}$ Національний університет кораблебудування ім. адм. Макарова, Украӥна

${ }^{2}$ Херсонська державна морська академія, Україна

\title{
РОЗРОБКА ВИСОКОЕФЕКТИВНОЇ СУДНОВОЇ СИСТЕМИ ОЧИЩЕННЯ ПОВІТРЯ ВІД КРАПЛИННОї ВОЛОГИ
}

\begin{abstract}
Досліджено один з напрямів підвищення техніко-економічних й екологічних показників двигунів та енергетичних установок шляхом очищення повітря як робочого тіла від краплинної вологи. Розглянуто перспективні методи сепараиії аерозольних середовищ з використанням градієнтної інтенсифікації процесів переносу в прикордонних шарах багатофункиіональних поверхонь. До багатофункиіональних поверхонь відносять поверхні 3 коефіцієнтом компактності більше ніж $2000 \mathrm{M}^{2} / \mathrm{M}^{3}, \quad я к і$ характеризуються підвищеними теплообмінними $i$ сепаруючими властивостями. Характерною особливістю розроблених сепаруючих профілів є поєднання хвилеподібної частини з плоскими вхідними та вихідними ділянками. У зборі сепаруючі профілі утворюють криволінійні канали з низкою послідовних конфузорних $i$ дифузорних ділянок. У дифузорних ділянках виникають відривні зони зі зворотною течією газу. Плівка рідини, щзо виникає внаслідок осадження крапель, потрапляючи в ці зони, сприймає вплив вихорів, які протидіють руху плівки у напрямку основного потоку $і$ сприяють ї̈ стоку під дією сили тяжіння.

Виконано дослідження газодинаміки та коефіцієнтів осадження сепараційного профілю. Розраховано коефіцієнт осадження краплинної вологи для швидкостей потоку 5, 10, 15, 20 м/с у сепаруючих профілях з радіусами 5, 10, 15, 20, 25 мм. Встановлено, щзо вихрові зони забезпечують повне відведення вловленої води з поверхні гладкого профілю до певної швидкості - $5 \mathrm{~m} / \mathrm{c}$. Перевищення иієї швидкості, призводить до виносу частини води з вихрових зон. Для запобігання вторинного обводнення потоку на плоских ділянках сепаруючого профілю, передбачені водовідвідні елементи. Розроблено конструктивні рішення та узагальнена схема суднової системи очищення повітря від краплинної вологи для витрат

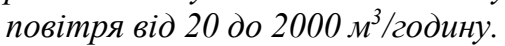

Впровадження фільтрів на основі градієнтних технологій дозволить підвищити надійність, ресурс суднового енергетичного обладнання та його елементів. Це сприятиме створенню високоефективних енергоресурсозберігаючих технологій та ефективних конструктивних рішень для широкого класу градієнтних сепараторів суднових енергетичних установок.
\end{abstract}

Ключові слова: система очищення; сепаратор; аерозольне середовище; коефічієнт осадження; швидкість потоку.

\section{1. Аналіз проблеми і постановка мети дослідження}

Актуальність проблеми сепарації фаз обумовлена впливом аерозольних середовищ у робочих тілах суднових двигунів та енергетичних установок на їхні техніко-економічні й екологічні показники [1]. В енергетичних установках цей вплив характеризується залежністю інтенсивності охолодження елементів проточної частини від стану їх забрудненості, якісного та кількісного складу шкідливих викидів у відпрацьованих газах, необоротних втрат води тощо.

У новому поколінні сепараційних повітроочисних пристроїв необхідно розширювати матеріалозберігаючі функції, а також застосовувати незадіяні раніше енергоресурси самих повітряних потоків для цілей очищення.

Інтенсифікація процесів осадження частинок один з ефективних способів зниження маси і габаритів, підвищення економічності та надійності роботи газоочисного пристрою.

\section{2. Аналіз досліджень і публікацій}

Існуючі сепараційні технології і пристрої здатні очищувати від частинок розміром більше 10 мкм 3 ефективністю не менше 0,99 [2, 3]. Очищення газових і рідких середовищ від частинок менше 10 мкм менш ефективне і потребує розробки газоочисного сепараційного обладнання, здатного уловлювати частинки таких розмірів і застосовувати ресурсозберігаючі можливості самих установок за рахунок використання енергії робочого тіла.

(C) А. П. Шевцов, С. С. Рижков 
В даний час застосовуються сепаратори інерційного типу, сепаруючі елементи яких мають краплевідбійні планки або є порожніми з внутрішнім дренуванням краплинної вологи. Випробування краплевловлювачів показали їх недостатню сепаруючу здатність і підвищений аеродинамічний опір. Крім того, виготовлення таких сепаруючих елементів відзначається великим обсягом робіт, що не піддаються механізації. Одним 3 напрямів вирішення проблеми є розробка високоефективних градієнтних сепараторів аерозольних середовищ для суднових енергетичних установок [4]. Створення технологій розділення аерозольних середовищ з використанням нових методів уловлювання фаз є значним резервом енергозбереження. Вельми перспективні методи сепарації з використанням градієнтної інтенсифікації процесів переносу в прикордонних шарах багатофункціональних поверхонь. До багатофункціональних поверхонь відносять поверхні з коефіцієнтом компактності більше ніж $2000 \mathrm{~m}^{2} / \mathrm{M}^{3}$, які характеризуються підвищеними теплообмінними і сепаруючими властивостями.

Мета дослідження - розробка суднових систем очищення повітря від краплинної вологи.

\section{2. Результати дослідження}

Процеси у суднових системах очищення повітря від краплинної вологи підпорядковані двом головним завданням: осадженню краплин на поверхні сепаруючих профілів і відведенню вловленої води у збірник-піддон без пошкодження плівки води, що утворилася, тобто без вторинного обводнення потоку. У криволінійному каналі краплини води, що транспортуються повітряним потоком під дією інерційних сил, осаджуються як на випуклій (лобовій), так і на вигнутій частині каналу.

Проведений аналіз показав, що в сепараційних каналах краплі осаджуються на випуклій і вигнутій частинах профілю в порівнювальних кількостях. Внаслідок цього на сепаруючих профілях для запобігання вторинного обводнення потоку необхідно встановлювати двосторонні водовідвідні елементи.

Характерною особливістю розроблених сепаруючих профілів $є$ поєднання хвилеподібної частини 3 плоскими вхідними та вихідними ділянками. У зборі сепаруючі профілі утворюють криволінійні канали 3 низкою послідовних конфузорних і дифузорних ділянок. У дифузорних ділянках виникають відривні зони зі зворотною течією газу. Плівка рідини, що виникає внаслідок осадження крапель, потрапляючи в ці зони, сприймає вплив вихорів, які протидіють руху плівки у напрямку основного потоку і сприяють ії стоку під дією сили тяжіння.

Вихрові зони забезпечують повне відведення вловленої води 3 поверхні гладкого профілю до певної швидкості - $5 \mathrm{~m} / \mathrm{c}$. Перевищення цієї швидкості, призводить до виносу частини води 3 вихрових зон. Для запобігання вторинного обводнення потоку на плоских ділянках сепаруючого профілю, передбачені водовідвідні елементи.

Для розробки суднових систем очищення повітря від краплинної вологи було досліджено сепаруючий профіль (рис. 1) 3 наступними параметрами: радіуси кривизни $\mathrm{R} 1=(0,05 \div 0,5) \cdot \mathrm{L}$; $\mathrm{R} 2=(0,01 \div 1,0) \cdot \mathrm{L}$; відстань між профілями (висота) $\mathrm{h}=(0,5 \div 5) \cdot \mathrm{R} 1$, довжиною 80 мм, кількість відвідних канавок - 2 зверху профілю та 2 знизу профілю (довжина канавки 3 мм та висота 2 мм). За результатами аналізу обрано радіуси кривизни профілю 5, 10, 15, 20, 25 мм.

Проведено розрахунок осадження (табл. 1) у сепаруючому профілі при діаметрах частинок $1 . .3$ мкм, концентраціях рідкої фази $\left(\mathrm{H}_{2} \mathrm{O}\right) 5,10,15$, $20 \%$ та діапазоні швидкостей $5,10,15,20$ м/с.

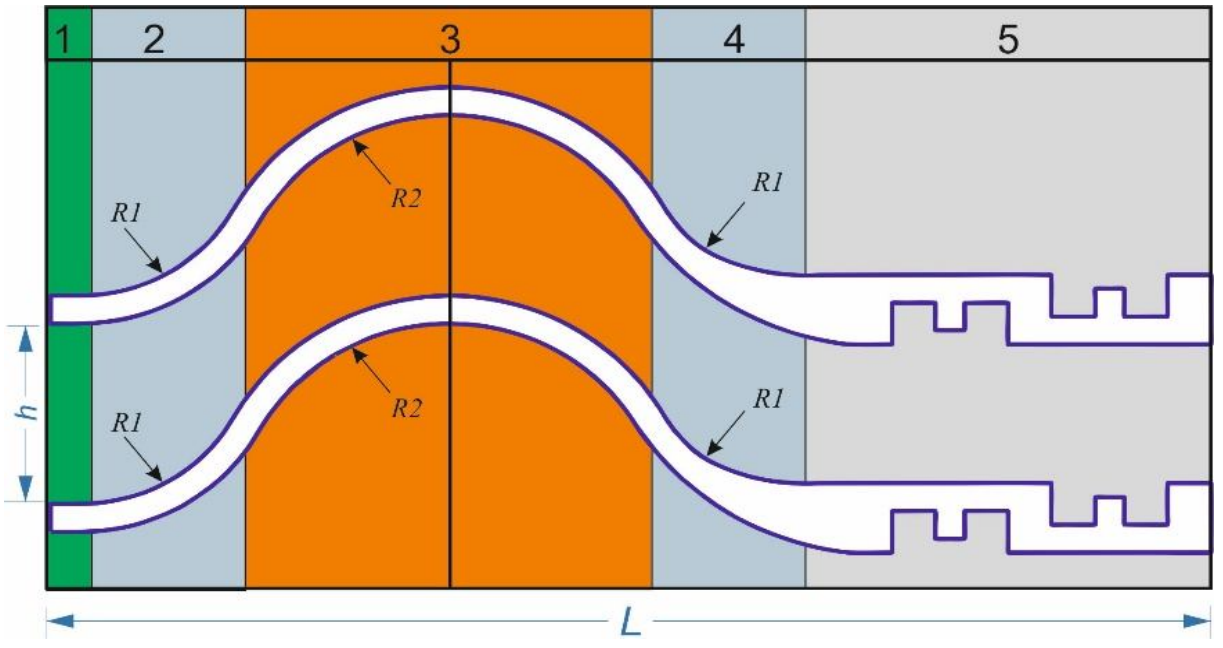

Рис. 1. Схема сепаруючих профілів з різними радіусами кривизни та розмірами 
Таблиця 1

Розрахунок коефіцієнта осадження в сепаруючому профілі

\begin{tabular}{|c|c|c|c|c|c|c|c|c|c|c|c|c|c|c|c|c|}
\hline \multirow{2}{*}{$\begin{array}{c}R \\
(\mathrm{MM})\end{array}$} & \multicolumn{4}{|c|}{$\mathrm{U}=5 \mathrm{~m} / \mathrm{c}$} & \multicolumn{4}{|c|}{$\mathrm{U}=10 \mathrm{~m} / \mathrm{c}$} & \multicolumn{4}{|c|}{$U=15 \mathrm{~m} / \mathrm{c}$} & \multicolumn{4}{|c|}{$\mathrm{U}=20 \mathrm{~m} / \mathrm{c}$} \\
\hline & $5 \%$ & $10 \%$ & $15 \%$ & $20 \%$ & $5 \%$ & $10 \%$ & $15 \%$ & $20 \%$ & $5 \%$ & $10 \%$ & $15 \%$ & $20 \%$ & $5 \%$ & $10 \%$ & $15 \%$ & $20 \%$ \\
\hline 5 & 35,7 & 34,7 & 35,8 & 36,1 & 31,3 & 31,2 & 31,4 & 30,2 & 25,9 & 24,8 & 25,7 & 26,4 & 20,8 & 20,6 & 20,4 & 20,2 \\
\hline 10 & 91,6 & 91,4 & 91,3 & 91,9 & 94,8 & 92,8 & 91,3 & 90,4 & 70,9 & 69,4 & 68,2 & 68,3 & 51,9 & 50,3 & 50,5 & 49,4 \\
\hline 15 & 99,9 & 99,9 & 99,9 & 99,9 & 99,6 & 99,3 & 99,4 & 99,1 & 82,3 & 82,4 & 83,5 & 84,9 & 74,9 & 73,5 & 74,1 & 73,8 \\
\hline 20 & 84,3 & 85,1 & 85,6 & 85,5 & 82,0 & 78,9 & 74,4 & 72,9 & 61,3 & 61,6 & 60,8 & 60,3 & 50,5 & 50,4 & 49,7 & 48,4 \\
\hline 25 & 42,5 & 42,1 & 41,9 & 41,2 & 32,0 & 32,5 & 31,3 & 31,4 & 22,7 & 22,4 & 21,8 & 21,4 & 15,4 & 15,1 & 15,9 & 14,6 \\
\hline
\end{tabular}

При розрахунку враховувалось, що у випадку збігання траєкторії руху частинок вони об'єднуються, а частинка вважається вловленою у випадку, якщо іiі траєкторія руху співпадає зі стінкою каналу.

За результатами розрахунків встановлено, що найбільш ефективні гідродинамічні характеристкики має канал довжиною 80 мм і радіусом 15 мм.
У результаті розрахунку було встановлено, що найбільш ефективним каналом осадження $є$ канал 3 радіусом 15 мм, а найбільш ефективний діапазон швидкостей $1 \ldots 10 \mathrm{M} / \mathrm{c}$.

На основі дослідження найбільш ефективного радіусу сепаруючого профілю та визначення робочих швидкостей у каналі була розроблена загальна схема високоефективної суднової системи очищення повітря від краплинної вологи (рис. 2).
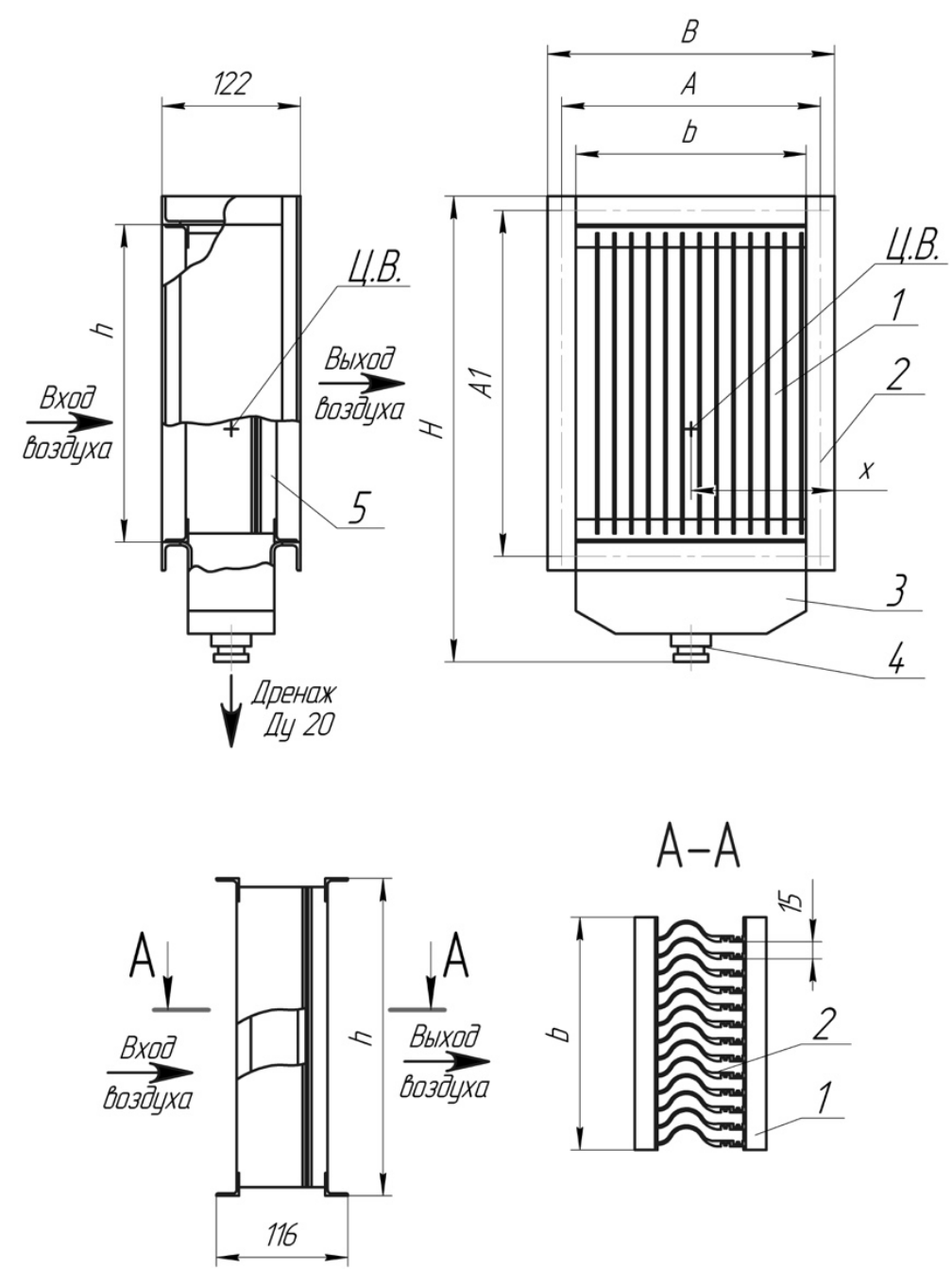

Рис. 2. Загальна схема суднової системи очищення повітря від краплинної вологи: 1 - сепаруючий профіль;

2 - фланець кріплення; 3 - піддон зливу; 4 - зливний патрубок; 5 - кріплення сепаруючого модулю; (для А -А: 1 - сепаруючий профіль; 2 - кріплення сепаруючого профілю); А, В A1, H, b, h - розміри обладнання 
На основі виконаних теоретичних та експериментальних досліджень було розроблено модельний ряд суднових систем очищення повітря від краплинної вологи.

Випробування водовіддільників показали, що коефіцієнт уловлювання при водності до 50 г/кг і швидкості повітря на вході до $10 \mathrm{M} /$ сек практично сягає $100 \%$. Результати дослідження аеродинамічного опору показали, що аеродинамічний опір при швидкості 5 м/сек становить $50 \mathrm{H} / \mathrm{M}^{2}$.

\section{Висновки}

Розраховано коефіцієнт осадження краплинної вологи для швидкостей потоку $5,10,15,20$ м/с у сепаруючих профілях 3 радіусами $5,10,15,20$, 25 мм. Розроблено конструктивні рішення суднових систем очищення повітря від краплинної вологи для витрат повітря від 20 до $2000 \mathrm{~m}^{3} /$ годину.

Впровадження фільтрів на основі градієнтних технологій дозволить підвищити надійність, ресурс суднового енергетичного обладнання та його елементів. Це сприятиме створенню високоефективних енергоресурсозберігаючих технологій та ефективних конструктивних рішень для широкого класу градієнтних сепараторів суднових енергетичних установок.

\section{Література}

1. Annex VI of MARPOL 73/78. Regulations for the Prevention of Air Pollution from Ships and NOx Technical Code [Text]. - IMO, London, UK MPG Books Ltd., 1998. - 150 p.
2. Filtration + Separation/Word Buyers' Guide and Directory [Text]. - Elsevier Science UK, 2005. $200 \mathrm{p}$.

3. A review of recent literature investigating of the measurement of automotive particulate; the relationship with environment aerosol, air quality and health effect [Text] / D. E. Hall, D. B. King, T. B. Morgan et al. // Ibid. - 1998. - № 982602. - P. 53-65.

4. Рыжков, С. С. Применение аэрозольных градиентных технологий в сепарационном оборудовании для судостроения и морской инфраструктуры [Текст] / С. С. Рыжкков // Судостроение и морская инфраструктура. - 2015. - № 2(4). - P. 151-163.

\section{References}

1. Annex VI of MARPOL 73/78. Regulations for the Prevention of Air Pollution from Ships and NOx Technical Code. IMO, London, UK MPG Books Ltd. $1998.150 \mathrm{p}$.

2. Filtration + Separation/Word Buyers' Guide and Directory, 2005, Elsevier Science UK. 200 p.

3. Hall, D. E. King, D. B., Morgan, T. B. et al. A review of recent literature investigating of the measurement of automotive particulate; the relationship with environment aerosol, air quality and health effect. Ibid, 1998, no. 982602, pp. 53-65.

4. Ryzhkov, S. S. Primenenie aerozolnyh gradientnyh tehnologiy v separacionnom oborudovanii dlja sudostroyeniya i morskoy infrastruktury [Use of aerosol gradient technologies in separation equipment for shipbuilding and marine infrastructure]. Sudostroyeniye $i$ morskaya infrastruktura - Shipbuilding \& Marine Infrastructure, 2015, no. 2(4), pp. 151-163.

Надійшла до редакиії 12.09.2018, розглянута на редколегї 3.10.2018

\section{РАЗРАБОТКА ВЫСОКОЭФФЕКТИВНОЙ СУДОВОЙ СИСТЕМЫ ОЧИСТКИ ВОЗДУХА ОТ КАПЕЛЬНОЙ ВЛАГИ}

\section{А. П. Шевцов, С. С. Рыжков}

Исследовано одно из направлений повышения технико-экономических и экологических показателей двигателей и энергетических установок путём очистки воздуха как рабочего тела от капельной влаги. Рассмотрены перспективные методы сепарации аэрозольных сред с использованием градиентной интенсификации процессов переноса в приграничных слоях многофункциональных поверхностей. К многофункциональным поверхностям относят поверхности с коэффициентом компактности более $2000 \mathrm{~m}^{2} / \mathrm{m}^{3}$, характеризующиеся повышенными теплообменными и сепарирующими свойствами. Характерной особенностью разработанных сепарирующих профилей является сочетание волнообразной части с плоскими входными и выходными участками. В сборе сепарирующие профили образуют криволинейные каналы с рядом последовательных конфузорных и диффузорных участков. В диффузорных участках возникают отрывные зоны с обратным течением газа. Плёнка жидкости, возникающее вследствие осаждения капель, попадая в эти зоны, воспринимает влияние вихрей, которые противодействуют движению плёнки в направлении основного потока и способствуют ее стоку под действием силы тяжести.

Выполнены исследования газодинамики и коэффициентов осаждения сепарационного профиля. Рассчитан коэффициент осаждения капельной влаги для скоростей потока 5, 10, 15, 20 м/с в сепарирующих профилях с радиусами $5,10,15,20,25$ мм. Установлено, что вихревые зоны обеспечивают полный отвод уловленной воды с поверхности гладкого профиля до определенной скорости - 5 м/с. Превышение этой ско- 
рости приводит к выносу части воды из вихревых зон. Для предотвращения вторичного обводнения потока на плоских участках сепарирующего профиля предусмотрены водоотводные элементы. Разработаны конструктивные решения и обобщенная схема судовой системы очистки воздуха от капельной влаги для расхода воздуха от 20 до 2000 м $^{3}$ час. Внедрение фильтров на основе градиентных технологий позволит повысить надежность, ресурс судового энергетического оборудования и его элементов. Это будет способствовать созданию высокоэффективных энергоресурсосберегающих технологий и эффективных конструктивных решений для широкого класса градиентных сепараторов судовых энергетических установок.

Ключевые слова: система очистки; сепаратор; аэрозольная среда; коэффициент осаждения; скорость потока.

\section{DEVELOPMENT OF A HIGH EFFICIENT SHIP SYSTEM OF AIR CLEANING OF CONDENSED MOISTURE}

\section{A. P. Shevtsov, S. S. Ryzhkov}

It is investigated one of the directions of increasing the technical, economic and environmental characteristics of engines and power plants by air cleaning as a working fluid of condensed moisture. Prospective methods of aerosol medium separation with the help of gradient intensification of transfer processes in boundary layers of multifunctional surfaces are also investigated. Multifunctional surfaces include surfaces with a coefficient of compactness more than $2000 \mathrm{~m} 2 / \mathrm{m} 3$, characterized by improved heat exchange and separating properties. A characteristic feature of the developed separating profiles is the combination of a waveform part with flat input and output elements. In the assembly, the separating profiles form the curved channels with a number of successive confuser and diffuser elements. In diffusor elements, there are separating zones with the gas reverse flow. The liquid film resulting from the droplets deposition, falling into these zones, is influenced by the vortices effect that counteracts the film motion in the direction of the main flow and facilitates its flow under the action of gravity.

The investigations of gas dynamics and deposition coefficients of the separation profile were performed. The coefficient of droplets deposition for flow rates of 5, 10, 15, $20 \mathrm{~m} / \mathrm{s}$ in separating profiles with a radius of 5, 10, 15, 20, $25 \mathrm{~mm}$ was calculated. It was determined that vortex zones provide full removal of captured water from the smooth surface profile up to the airspeed of $5 \mathrm{~m} / \mathrm{s}$. Excess of this speed leads to the removal of part of the water from the vortex zones. Drainage elements are provided for preventing secondary flooding of the flow in flat sections of the separation profile. Design solutions and a generalized scheme of the ship system of air cleaning of condensed moisture for the air flow from 20 to $2000 \mathrm{~m} 3 / \mathrm{h}$ were developed. The introduction of filters based on gradient technologies will increase the reliability, the life of the marine power equipment and its elements. This will contribute to the creation of high-efficiency energy-saving technologies and efficient design solutions for a wide range of gradient marine power plant separators.

Keywords: cleaning system; separator; aerosol medium; deposition coefficient; flow rate.

Шевцов Анатолій Павлович - д-р техн. наук, проф., зав. кафедри системотехніки морської інфраструктури і енергетичного менеджменту Національного університету кораблебудування ім. адмірала Макарова, Миколаїв, e-mail: aootnet@ukr.net.

Рижков Сергій Сергійович - д-р техн. наук, проф. Херсонської державної морської академії, Херсон, Україна, e-mail: ryzhkov.sergiy@gmail.com.

Shevtsov Anatoliy Pavlovych - Doctor of Technical Science, Professor, Head of System Technics of Sea Infrastructure and Energy Management Chair of Admiral Makarov National University of Shipbuilding, Mykolaiv, Ukraine, e-mail: aootnet@ukr.net.

Ryzhkov Serhiy Sergiyovych - Doctor of Technical Science, Professor of Kherson Marine University, Kherson, Ukraine, e-mail: ryzhkov.sergiy@gmail.com. 